\title{
The use of sprouted barley grain in the diet of meat hens of the parent herd
}

\author{
Olga Tatiyanicheva ${ }^{1}$, Oksana Popova ${ }^{1}$, Alla Khokhlova $^{1}$, Natalya Maslova ${ }^{1 *}$, and Tatiyana \\ Ovchinnikova $^{1}$ \\ ${ }^{1}$ Belgorod State Agrarian University named after V.Ya.Gorina, 24, Vavilova str., 308503, Belgorod, \\ Russia
}

\begin{abstract}
The use of sprouted barley grain for an adult poultry of a parent flock of meat production is of scientific and practical interest. According to the research methodology, we formed 4 groups of experimental birds, at the age of 140 days, 10 chickens and 10 cockerels in each. The test period lasted 280 days. The poultry of the control group received a standard complete feed containing barley grains in an amount of $20 \%$ by weight of the compound feed, in accordance with the adopted feeding scheme. Poultry of groups 2,3,4 received in addition to the main diet sprouted barley grain in the amount of $20 \mathrm{~g}$ per head. In this experiment, the question of the effectiveness of using sprouted grain, depending on the feeding regime, was considered. A positive trend was revealed when feeding sprouted grain in addition to a complete feed, in the evening.
\end{abstract}

\section{Introduction}

The industrial poultry industry differs from other livestock industries in its rapid reproduction rates and lower financial costs per unit of production. Commercial farms producing poultry products throughout the calendar year evenly produce poultry products these are mainly eggs and meat. These products are very important for humans and are mainly a source of food resources.

Today, crosses are used for the production of meat and eggs. The cross is a biological machine and it is important that its design is resource-efficient.

The efficiency of industrial poultry farming depends on what crosses are used at a given breeding enterprise, their genetic potential. Leading foreign breeding companies used highly productive poultry, there is an accumulation of genetic potential. This genetic material can represent the compatibility of dozens of lines and populations. Both domestic and foreign large firms are involved in this process. In the Belgorod region, crosses of foreign selection are used at all industrial enterprises. These crosses differ in production, but the consumer's demand is also taken into account here [1,2].

Industrial poultry farming has changed radically over the past decades. This industry is developing very rapidly as a large, technically equipped industrial branch of agricultural

\footnotetext{
* Corresponding author: natasha-maslova@mail.ru
} 
production, its intensification is based on the fact that the development of the egg and meat direction takes place at a sufficient level.

The main point of the successful development of meat and egg poultry farming is the use of biologically complete and high-calorie poultry feeding. The application of the effect of heterosis, this happens by crossing proven for many years, for compatibility of breeds and lines of chickens, and the end result is obtaining highly genetically potential crosses.

But nevertheless, the Russian poultry industry lags behind in this regard, although in recent years a lot of work has been carried out to develop certain methods in poultry meat farming. To improve the reproduction of chickens in the meat direction of productivity. Specialized lines of poultry have become more widely used when crossing which a large number of meat chickens are obtained.

The experience of leading enterprises in the meat sector of productivity testifies to the fact that further improvement of the technology of growing and keeping meat poultry allows improving the quality and economic indicators.

In the Russian Federation, there is a large number of Poultry Industry facilities that are not involved in the production of poultry products. Of course, this potential can be used in the further development of domestic poultry farming, both in the domestic market and in the foreign market. Assessing the current situation in Russia for the production of poultry products and the prospect for 5 years, it is envisaged that these figures will be as follows: 46.6.5 bil. pieces, and meat 5.5 mil. tones. These are quite good indicators and it is possible to achieve these indicators due to the introduction of new high-tech modernized equipped enterprises into operation. And also, naturally, if productivity indicators are systematically improved.

Such measures will significantly increase the production of poultry products, increase the output of these products per unit area by $7-8 \%$, and thereby significantly reduce the consumption of energy resources by $1.5-2$ times.

The modern technology of growing laying hens of meat production direction provides for an optimal light regime, the use of modern ventilation equipment, the use of a balanced dry concentrate type of feeding, heating, and feeding and drinking lines, regulated by computer systems. All this made it possible to obtain up to 250 eggs per laying hen of the parent flock [3-6].

Further development of the industry will largely be determined by the level of breeding work, the introduction of new breeding achievements, the improvement of crosses in increasing their egg and meat productivity, as well as an increase in the safety of poultry and, at the same time, reducing the cost of growing.

At the moment, the world produces $28 \mathrm{~g}$ of protein per person per day. In developed countries, protein per person per day is produced at 90-100 g (USA, Canada, Belarus), in Germany, France and Spain, 70-80 g of protein per person per day is produced, in New Zealand - more than $500 \mathrm{~g}$. In Russia, the amount of protein produced per person / day is only $43 \mathrm{~g}$, which is clearly not enough.

In Russia, the market for eggs and egg products is formed at the expense of domestic production. The Belgorod region is in 1st place in terms of growth rates and gross production of poultry meat in Russia. Currently, a long-term target program "Development of poultry farming in the Belgorod region for 2016-2020" has been developed.

This program is a continuation of the national project "Development of the agroindustrial complex". In 2019, the Belgorod region produced 646 thousand tons of poultry meat in live weight and 1 billion 399 million pieces eggs. For each inhabitant of our 1.5 million region, about $360 \mathrm{~kg}$ of poultry meat in live weight (or $250 \mathrm{~kg}$ in slaughter weight) and 800 eggs are produced annually, which is 14 and 3 times more than the national average, respectively. 
With the further development of industrial poultry farming, it is necessary to use innovative developments in the field of feeding and keeping poultry. Poultry farming methods are based on the use of highly productive lines and crosses. For the further development of industrial poultry farming, further scientific developments are required [7].

The challenge for the poultry industry is to improve the efficiency of enterprises, ensuring the biological safety and competitiveness of products. And this can be achieved only with the introduction of new technologies.

Fodder production is an industry that is one of the main industries in agriculture. The development of this industry has a huge impact on the level and quality of products obtained from the poultry industry. Speaking about the egg productivity of laying hens, at the initial stage, hens have an egg mass of 35-45 g. The ratio of the components (protein, yolk, shell) is 6: 3: 1. During the productive period, egg production and egg weight change. This happens with the age of the laying hens. The productive period is estimated in 4-week segments. And then, in general, for the entire productive period.

There are many factors contributing to the increase in poultry production. One such factor is the use of complete, balanced diets.

To obtain hatching eggs in modern industrial production, highly hybrid crosses are used. In such crosses, at the age of 20-28 weeks there is an increase in egg production. The development of selection of modern meat crosses is taking place at a rapid pace. These crosses, newly created crosses, are distinguished by low feed costs for production, intensive metabolism and high-quality products $[8,9]$.

These are foreign meat crosses Arbor Acres, Kobb-500, Ross-308, which operate in the Belgorod region. From the parental herds of the above crosses, hatching eggs are obtained, which have high rates of fertility and hatchability of young animals. One of the indicators of the implementation of the genetic material of modern highly productive crosses is the complete feeding of the bird. This usefulness depends on the biological value of the diet. Reducing feed costs for the production of poultry products, and most importantly obtaining these high quality products, is the main task of the development of modern poultry farming.

But not only the use of balanced complete feeds affects productivity indicators, but also the creation of optimal conditions for keeping. In general, it can be noted that the technology for the production of hatching eggs is a system of knowledge with rational methods of raising poultry, its reproduction, feeding and keeping. Of course, such sciences should be taken into account and used here: as selection, zoology, and genetics.

The positive dynamics of the development of industrial poultry farming due to the introduction of Western technologies and crosses, allows us to speak of serious results in this area. Using chemicals. By using various stimulants and antibiotics, it is possible to achieve minor positive results in increasing productivity [10].

There is a certain experience using sprouted cereal grains in poultry feeding - these are wheat, oats, and barley. This is used with the aim of increasing poultry production, as well as contributing to a positive effect on their physiological state. When using computer systems, components are selected that are optimal for a particular cross.

By strengthening the bird's immunity, a whole spectrum of diseases can be excluded. The World Health Organization has developed a scale for the adult requirement for essential amino acids.

In the conditions of intensive development of poultry farming, product quality becomes an important criterion. Within normal standard poultry diets, the effect of protein on egg quality is more consistent. Currently, broiler production is developing in the face of fierce competition between the world's leading breeding companies.

Therefore, breeding plants and testing stations, together with scientists from AllRussian Research and Technological Institute of Poultry and other scientific institutions, are constantly working to improve the poultry of the initial lines, adjusting the breeding, 
veterinary and technological programs, using domestic and foreign innovative developments.

A decrease in feed conversion is one of the main signs of efficiency in broiler production. To increase the live weight of a bird and maintain its high reproductive qualities, modern programs have been created. They include an annual assessment of parent forms and broilers.

When growing laying hens of meat production direction, part of it is used with whole grain. But there is an opinion of some authors to use sprouted grain, this will significantly improve the quality of the products obtained, as well as significantly increase the safety of livestock. Barley grain is a fodder crop that is often used for germination; it has high agrotechnical qualities $[11,12]$.

Many authors in their works reflect the issue of using sprouted grain in growing poultry. But there is not enough information that concerns the study of the influence of this fodder product on the productive and reproductive qualities of breeding birds of the meat direction of productivity. Moreover, the mode of feeding the sprouted grain of barley to this group of birds has not been studied and developed.

This feed product is a dietary supplement that poultry uses in their daily diet. Sprouted barley has a low calorie content. $100 \mathrm{~g}$ of the product contains $160 \mathrm{kcal}$. More than $50 \%$ is water, carbohydrates $-31 \mathrm{~g}$, proteins $-5.7 \mathrm{~g}$, fats -5.7 , there is dietary fiber $(8.3 \mathrm{~g})$ and ash $(1.3 \mathrm{~g})$. An important factor is the high digestibility of carbohydrates, which satisfy energy requirements.

The chemical composition of this feed product is represented by the following components:

vitamins B1 and B6 - these vitamins provide the body with energy, help to strengthen the immune system, take part in the functioning of the nervous system and have a positive effect on the normal formation of erythrocytes;

choline (vitamin B4) - is an important substance that has a positive effect on the functioning of the nervous system, regulates insulin in the blood; sterols - are organic compounds that allow the concentration of cholesterol;

essential amino acids - help to increase the body's resistance to diseases, contribute to the participation in the normalization of the liver and kidneys;

nonessential amino acids - promote cell regeneration, are a building material for all organs and systems;

biotin (vitamin B7) - participates in the normalization of blood sugar levels, improves metabolism.

When compiling rations for poultry, its biological characteristics are taken into account. These features include: species, breed, lines and crosses used, level of productivity, age, sex, individual characteristics [13].

If we compare the metabolism of poultry in the egg and meat directions of productivity, then it can be noted that meat poultry has a lower metabolism. Moreover, such a bird has the ability to overeat. In addition, for the parent flock this is a negative moment, the bird becomes fat, thereby reducing egg production.

Poultry feeding program for parent flocks: Starter: 0-5 weeks. Here it is necessary to use limited feeding for females and males; the feed is distributed in the form of crumbs. At the initial stage of feeding, compound feed of the PK-2 brand is used, from 2 to 5 weeks of feeding the young animals, compound feed of the PK-4 brand is used. By the end of the rearing period, replacement chicks consume about 42 grams for 1 head. The nutritional value of the compound feed is $19 \%$ of crude protein. The live weight of the bird at the end of this growing period is 560 grams.

Growth: 5-18 weeks. This is the period characterized when the feed restriction is used at its maximum. The food is characterized by the following structure. Loose, low-energy 
feed. To achieve 40-60 minutes of feeding time, hungry days are introduced ( 5 feeding days out of 7). During this period, from 6 to 12 weeks, the compound feed of the PK-3 brand is fed, and then the compound feed of the PK-4 brand. The transition to feed of the first part of productivity No. 1 when the first eggs appear. Live weight at the end of the growing period is about 1830 grams. The content of crude protein in complete feed is $15 \%$. One head accounts for 90 grams of compound feed.

Pre-lay period: 19-31 weeks. This is the feed for the first half of the productive period. This period is characterized by the fact that the bird is still growing, is on the rise of egg production. Therefore, feed must contain high levels of linoleic acid and proteins.

Increase the level of vitamins in the diet by $20 \%$ at the beginning of productivity. At the same time, they feed the PK-4 transitional compound feed (141-147 days), PK-4 pre-lay (from 148 days to 5\% productivity), and PK-1-1 peak. Crude protein in feed contains 16\%. The live weight of the bird at the end of the period is $3440 \mathrm{~kg}$. The daily amount of feed consumed is 130 grams.

Feed for the second growing period. This food contains less energy and protein. There are the same amount of minerals in this feed, except for phosphorus, the amount of which is reduced. During this period, compound feeds of the brand PK-1-1 (218-280 days), PK-1-2 (281 days before slaughter), compound feed PK-8 (141 days before slaughter) are used this is for males [14].

For males up to 20 weeks of age, feed is used according to the same recipes as for hens. From the 20th week, after the transfer of poultry from the breeding area to the parent flock keeping area, the males are fed food according to the PK-8 recipe with an exchange energy content of $265 \mathrm{Kcal}$ and $14 \%$ crude protein. To increase the incubation qualities of eggs in the second half of the day, the bird is additionally given a shell with a particle size of $1.5-2.5 \mathrm{~mm}$ to the bird feeders.

For males, sprouted oat grains are added to the general feeding on the farm. It is a food with a reduced protein and calcium content, which helps males to be active and healthy, and also helps to increase the fertility of hatching eggs.

Feeding of males in the establishment takes place under the supervision of operators to make sure that they find feed and eat it at their rate in the time allotted for feeding.

The feed rate for males depends on their live weight. Emaciated and very passive males, sick males are removed from the flock, as well as males with a large live weight. In addition, non-working roosters bring considerable harm to the enterprise. Existing technology where hens and males are kept separate from each other until at least 6 weeks of age. But in most breeding farms, to achieve the best result, males and hens are reared separately for up to $20-21$ weeks.

Full-fledged complex of vitamins, which is contained in this feed product, will contribute to the normal growth of the body, improve the condition of cartilage and bone tissue, and will also make its own contribution to strengthening immunity $[15,16]$.

The use of this product contributes to an increase in the body's content of antibacterial and antiviral substances, which are so necessary. Dietary fibers, which are part of the germinated grains, cleanse the body of harmful elements, thereby lowering blood sugar levels.

\section{Research methodology}

All of the above questions served as a moment to identify how the productivity indicators of poultry of the meat direction of productivity, feeding of germinated barley grain, affect. At this enterprise, where the experiment was carried out, the Ross-308 cross of foreign selection is used. The task was to study the main productive and reproductive qualities in the hens of the parent flock. 
The experiment was carried out in a production environment during the period 20182020. The use of sprouted barley grain by an adult poultry population of a parent flock of meat productivity is of scientific and practical interest. According to the research methodology, we formed 4 groups of experimental birds, at the age of 140 days, 10 chickens and 10 cockerels in each. The test period lasted 280 days. The poultry of the control group received a standard complete feed containing barley grains in an amount of $20 \%$ by weight of the compound feed, in accordance with the adopted feeding scheme.

Poultry of groups 2,3,4 received in addition to the main diet sprouted barley grain in the amount of $20 \mathrm{~g}$ per head. In this experiment, the question of the effectiveness of using sprouted grain, depending on the feeding regime, was considered. A positive trend was revealed when feeding sprouted grain in addition to a complete feed, in the evening.

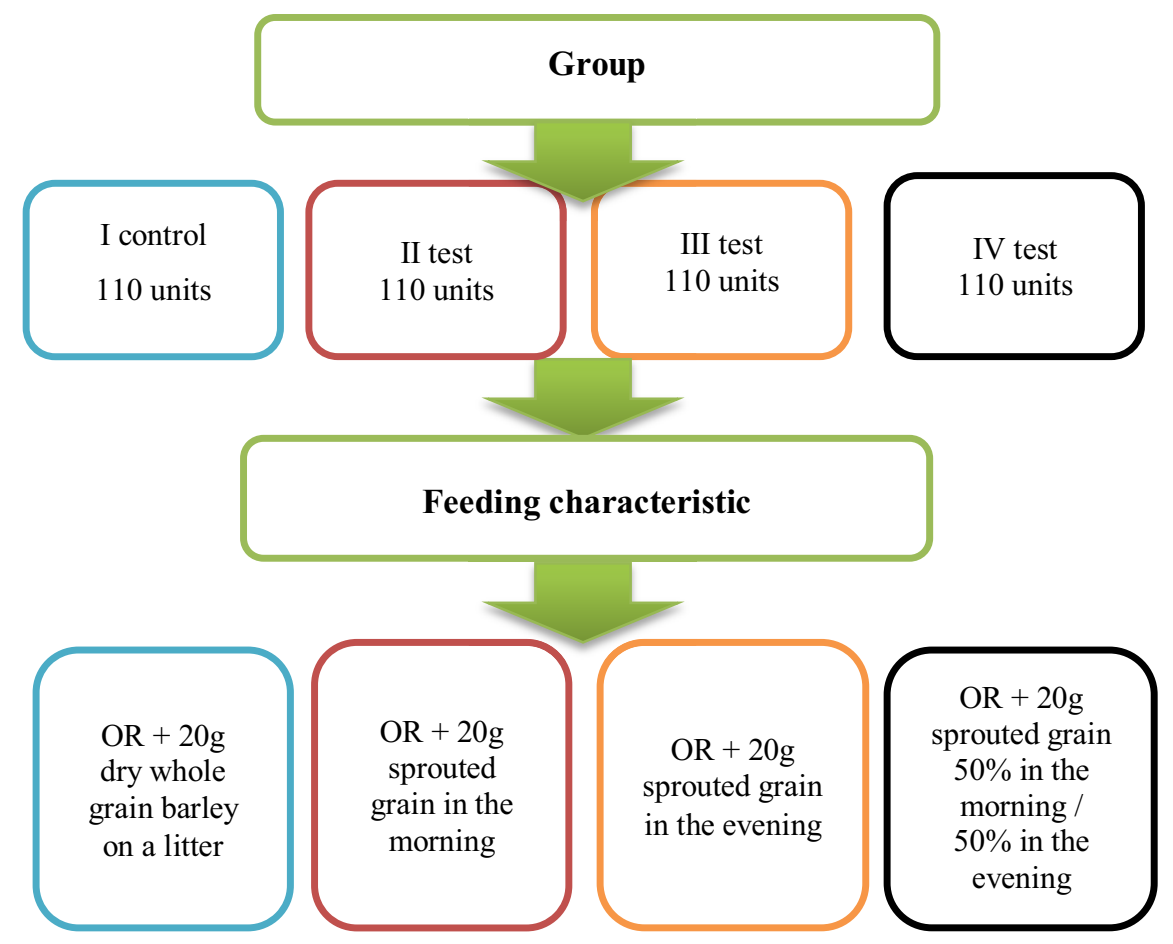

Fig. 1. Experiment scheme.

The technology for obtaining sprouted grains consists in soaking barley grains in water at a certain temperature and aging period. The cleaned and previously prepared grain is scattered into trays with a side height of $2.5 \mathrm{~cm}$ at the rate of $4.0 \mathrm{~kg}$ of grain per $1 \mathrm{~m}^{2}$ of area. The tap water used is preheated to a temperature of $20-250^{\circ} \mathrm{C}$. The ambient temperature, which contributes to the simultaneous germination of grain, should be at least $20-260^{\circ} \mathrm{C}$. Throughout the entire time of obtaining a feed additive, barley grain is watered with water of the same temperature, 2 times a day using sprayers. Germination of grain is carried out to an average height of sprouts of $0.5-2.0 \mathrm{~cm}$, then it is used as an additive to the basic diet of animals. The scheme of the experiment is shown in Figure 1.

To study the effect of the feed additive from sprouted barley grain in the diets of the parent flock, we conducted studies aimed at studying the live weight of poultry, at the beginning, middle and at the end of the experiment, the safety of the livestock throughout the entire growing period and productivity indicators such as egg production, egg weight, hatching eggs yield, fertility and hatchability of eggs, young stock yield. 


\section{Research results}

One of the important indicators taken into account as a result of the study is the change in the mass of eggs of meat poultry. It should be noted that it was significantly higher in the experimental group of hens. If we consider this excess in terms of age periods, it should be noted that at the age of 28 weeks, the excess was $31 \%$, at the age of 40 weeks, slightly less $2.3 \%$, at the age of 60 weeks of chickens, data were obtained on the excess weight of eggs by $3.7 \%$.

When receiving a hatching egg, an important quality indicator is the suitability of eggs for incubation, that is, the absence of various damage to the outside and inside of the egg. Characterizing these indicators presented in table 2, it should be noted that in birds of experimental groups II-IV, the hatching egg yield was 1.2 higher; 1.7 and $1.4 \%$, respectively, than in the control group, where the yield was $91.6 \%$.

Table 1. Yield of hatching eggs, $\%$.

\begin{tabular}{|l|c|c|c|c|}
\hline \multirow{2}{*}{\multicolumn{1}{|c|}{ Indicators }} & \multicolumn{4}{c|}{ Group } \\
\cline { 2 - 5 } & $\begin{array}{c}\text { I } \\
\text { control }\end{array}$ & $\begin{array}{c}\text { II } \\
\text { test }\end{array}$ & $\begin{array}{c}\text { III } \\
\text { test }\end{array}$ & $\begin{array}{c}\text { IV } \\
\text { test }\end{array}$ \\
\hline Eggs unfit for incubation: & & & & \\
\hline fight and notch & 3.8 & 3.6 & 3.5 & 3.4 \\
\hline small & 0.8 & 0.7 & 0.5 & 0.7 \\
\hline two-yolk & 0.6 & 0.4 & 0.3 & 0.5 \\
\hline irregular shape & 1.2 & 1.1 & 1.2 & 1.2 \\
\hline marbling of the shell & 1.3 & 1.0 & 0.7 & 0.7 \\
\hline shell growth & 0.4 & 0.3 & 0.3 & 0.3 \\
\hline blood inclusions & 0.3 & 0.2 & 0.2 & 0.2 \\
\hline Total rejected & 8.4 & 7.3 & 6.7 & 7.1 \\
\hline Hatchery egg yield & 91.6 & 92.8 & 93.3 & 93.0 \\
\hline
\end{tabular}

As is known from the experience of many domestic and foreign scientists, for the realization of the genetic potential in modern breeds and crosses of farm animals and poultry, it is not enough to have outstanding qualities that are inherited. The incubation results are shown in Table 2.

Fifty percent of success in breeding such animals and poultry is complete feeding balanced in all nutrients, in accordance with age and physiological needs, in a word, feeding biologically complete rations. Analyzing the data obtained as a result of the study on the inclusion of sprouted barley grain in the diet of adult laying hens, it can be concluded that this additive had a significant impact not only on the yield or quantitative indicators of hatching eggs, but also on the result obtained after the biological control of the incubation of chicken eggs.

Characterizing the data in Table 2, it should be noted that the percentage of fertilized eggs in experimental groups II - IV significantly exceeded this indicator in the control $(82.6 \%)$ by $1.3 ; 1.5$ and $1.4 \%$, respectively. Especially, we note the excess in groups III and IV. The number of conditioned youngsters hatched from the number of fertilized eggs was also higher in the experimental groups when feeding the germinated barley grain, and the third experimental group of laying hens was characterized by the highest rate of hatchability. The percentage of hatchability in it exceeded the control group by $2.3 \%$, in the second group, respectively - $0.5 \%$ and in the fourth - $1.6 \%$. An excellent result was obtained in terms of hatch rate, which is characterized by the percentage of viable young stock out of the number of incubated eggs. So, if in the control group this indicator was $72.4 \%$, then in the experimental groups it exceeded by $1.6 \% ; 3.2 \%$ and $2.7 \%$ respectively. 
Table 2. Results of egg incubation, $\%$.

\begin{tabular}{|l|c|c|c|c|}
\hline \multirow{2}{*}{\multicolumn{1}{|c|}{ Indicators }} & \multicolumn{4}{c|}{ Group } \\
\cline { 2 - 5 } & $\begin{array}{c}\text { I } \\
\text { control }\end{array}$ & $\begin{array}{c}\text { II } \\
\text { test }\end{array}$ & $\begin{array}{c}\text { III } \\
\text { test }\end{array}$ & $\begin{array}{c}\text { IV } \\
\text { test }\end{array}$ \\
\hline Fertility of eggs & 82.6 & 83.9 & 84.1 & 84.0 \\
\hline Hatchability of eggs & 87.6 & 88.1 & 89.9 & 89.2 \\
\hline Conclusion of young animals & 72.4 & 74.0 & 75.6 & 75.1 \\
\hline Incubation waste, including: & & & & \\
\hline unfertilized egg & 17.4 & 16.8 & 15.9 & 16.0 \\
\hline blood ring & 3.0 & 2.7 & 2.5 & 2.6 \\
\hline frozen embryos & 2.8 & 2.2 & 2.0 & 2.1 \\
\hline weakling & 3.0 & 3.0 & 3.0 & 2.9 \\
\hline weak and crippled & 1.4 & 1.2 & 1.0 & 1.1 \\
\hline
\end{tabular}

One of the important indicators in the biological control of egg incubation is the percentage of waste, which includes unfertilized eggs, embryos with various pathologies. From the analysis of the data obtained in Table 2, we can say that this indicator was the lowest in the III experimental group, $1.5 \%$ lower than in the control and $0.9 \%$ and $0.1 \%$ lower than in the II and IV groups respectively.

Analyzing the data obtained in Tables 2 and 3, we can conclude that the addition of sprouted barley grain to the main rations of poultry meat when receiving an incubation egg, regardless of the method and time of introduction, has a positive effect on the incubation and biological qualities of eggs. This is due to the content of riboflavin, vitamin $\mathrm{E}$ and vitamin A precursors - carotenoids. All of them, as a rule, are an important link in the general metabolism and correspond to the reproductive function of a living organism.

In industrial poultry farming with crowded keeping, excluding an individual approach to poultry feeding, an important indicator of productivity is egg production, which, as you know, is closely related to the genetic and technological component of the production of meat and poultry eggs.

The egg production index is calculated for the average and initial laying hen in the flock. In our studies, the calculation of egg production per initial hen is given. The data are presented in Table 3.

Analyzing the obtained results of egg production of meat poultry, we can say that in the third experimental group the excess for this indicator was $3.7 \%$ compared to the control group. In the second and fourth groups, egg production exceeded the control by 1.1 and $2.8 \%$, respectively.

It should be noted that the indicator of live weight was practically the same in the experimental and control groups in all periods taken into account. This is very important when raising breeder hens. The indicator of the safety of the adult livestock is no less important. In all groups with the addition of sprouted grain of barley to the main diet, this indicator was $93 \%$, which is $1.0 \%$ higher than in the control group with the main diet.

When feeding poultry, it is necessary to strictly adhere to a regimen that requires feeding at the same time. The addition of sprouted grain to the poultry diet is not just an additional opportunity, but a real necessity.

To increase the safety of livestock, productivity and incubation qualities of eggs, we recommend that it is advisable to feed the parent flock of beef breeds to the poultry in addition to full-feed compound feed with sprouted barley grain instead of dry, in the evening. 
Table 3. Technological indicators of hens of the parent flock.

\begin{tabular}{|l|c|c|c|c|}
\hline \multirow{2}{*}{ Indicators } & \multicolumn{4}{c|}{ Group } \\
\cline { 2 - 5 } & $\begin{array}{c}\text { I } \\
\text { control }\end{array}$ & $\begin{array}{c}\text { II } \\
\text { test }\end{array}$ & $\begin{array}{c}\text { III } \\
\text { test }\end{array}$ & $\begin{array}{c}\text { IV } \\
\text { test }\end{array}$ \\
\hline Safety,\% $\%$ & 92.0 & 93.0 & 93.0 & 93.0 \\
\hline Egg production for the initial hen, pcs & 181 & 183 & 188 & 186 \\
\hline Hatchery egg yield,\% & 91.4 & 93.4 & 93.5 & 93.5 \\
\hline Hatchability of eggs, \% & 82.7 & 84.2 & 84.4 & 84.4 \\
\hline Hatchery of young,\% & 72.6 & 75.3 & 75.8 & 75.2 \\
\hline
\end{tabular}

\section{References}

1. C. Gerpe, A. Stratmann, R. Bruckmaier, M. J. Toscano, Journal of Applied Poultry Research, 30, (Cover date: March 2021), (2020) https://doi.org/10.1016/j.japr.2020.100115

2. M. K. Sharma, D. White, C. Chen, et al., Poultry Science Available online (2021) https://doi.org/10.1016/j.psj.2020.12.030

3. Y. F. Gu, Y. P. Chen, R. Jin, et al., Poultry Science Available online (2021) https://doi.org/10.1016/j.psj.2020.12.046

4. K. Damaziak, J. Riedel, A. Marzec, et al., Animal Feed Science and Technology, 271 (2020) https://doi.org/10.1016/j.anifeedsci.2020.114729

5. S. Saraiva, C. Saraiva, I. Oliveira, G. Stilwell, A. Esteves, Poultry Science Available online (2020) https://doi.org/10.1016/j.psj.2020.12.012

6. X. Teng, W. Zhang, D. Xu, et al., Preventive Veterinary Medicine, 181 (2020) https://doi.org/10.1016/j.prevetmed.2020.105049

7. L. Gan, Y. Zhao, T. Mahmood, Y. Guo, Poultry Science, 99, 3594-3605 (2020) https://doi.org/10.1016/j.psj.2020.04.007

8. D. Li, Q. Tong, Z. Shi, et al., Poultry Science, 99, 3784-3792 (2020) https://doi.org/10.1016/j.psj.2020.03.060

9. I. P. Ogbuewu, V. M. Okoro, C. A. Mbajiorgu, Animal Feed Science and Technology Available online (2021) https://doi.org/10.1016/j.anifeedsci.2021.114866

10. L. Zhang, H. Sun, Z. Rao, et al., Biosystems Engineering, 200, 188-199 (2020) https://doi.org/10.1016/j.biosystemseng.2020.10.004

11. V. Pirgozliev, S. P. Rose, T. Pellny, et al., Poultry Science, 94, 232-239 (2015) http://dx.doi.org/10.3382/ps/peu059

12. J.L.Damasceno, C.S.Rocha, C.Eyng, et al., Livestock Science, 241 (2020) https://doi.org/10.1016/j.livsci.2020.104232

13. M.M. Khalil, M.R. Abdollahi, F. Zaefarian, et al., Animal Feed Science and Technology, 271 (2020) https://doi.org/10.1016/j.anifeedsci.2020.114754

14. M. R. Abdollahi, F. Zaefarian, L. Hall, et al., Poultry Science, 99, 5037-5046 (2020) https://doi.org/10.1016/j.psj.2020.06.056

15. S.-B. Wu, R. A. Swick, J. Noblet, et al., Poultry Science, 98, 1222-1234 (2019) ttp://dx.doi.org/10.3382/ps/pey442

16. A. N. Dobudko, O. E. Tatyanicheva, I.A. Boyko, et al., Research Journal of Pharmaceutical, Biological and Chemical Sciences, 9 (6), 1551-1559 (2018) 